\title{
Overexpression of IC53d promotes the proliferation of gastric cancer cells by activating the AKT/GSK3ß/cyclin D1 signaling pathway
}

\author{
JIAN-XIAN LIN ${ }^{1-3^{*}}$, XIN-SHENG XIE ${ }^{1-3^{*}}$, XIONG-FENG WENG ${ }^{1-3^{*}}$, SHENG-LIANG QIU ${ }^{4}$, JIAN-WEI XIE $^{1-3}$, \\ JIA-BIN WANG ${ }^{1-3}$, JUN LU $^{1-3}$, QI-YUE CHEN ${ }^{1,2}$, LONG-LONG CAO ${ }^{1,2}$, MI LIN ${ }^{1,2}$, RU-HONG TU ${ }^{1,2}$, \\ PING $\mathrm{LI}^{1-3}$, CHANG-MING HUANG ${ }^{1-3}$ and CHAO-HUI ZHENG ${ }^{1-3}$ \\ ${ }^{1}$ Department of Gastric Surgery, Fujian Medical University Union Hospital, Fuzhou, Fujian 350001; \\ ${ }^{2}$ Key Laboratory of Ministry of Education of Gastrointestinal Cancer; ${ }^{3}$ Fujian Key Laboratory of Tumor Microbiology, \\ Fujian Medical University, Fuzhou, Fujian 350108; ${ }^{4}$ Department of Pathology, Fujian Medical University Union Hospital, \\ Fuzhou, Fujian 350001, P.R. China
}

Received July 10, 2018; Accepted February 4, 2019

DOI: $10.3892 /$ or.2019.7042

\begin{abstract}
Cyclin-dependent kinase 5 regulatory subunitassociated protein 3 (CDK5RAP3 or C53) is involved in the development of various types of tumor, and alternative splicing of C53 results in numerous transcription variants that encode different isoforms. The present study aimed to clone human C53 isoform d (IC53d) and explore its role in the proliferation of gastric cancer cells. Reverse transcription-quantitative polymerase chain reaction was used to detect the expression levels of IC53d in 80 primary gastric adenocarcinoma tissues and adjacent normal tissues. In addition, the association between IC53d and clinicopathological parameters was determined. Gastric cancer cell lines stably overexpressing IC53d were established to observe its effects on cell proliferation, invasion and migration, and on in vivo tumorigenicity, and the mechanism of action was explored. The results of the presen study demonstrated that IC53d was upregulated in gastric cancer tissues and was associated with tumor T-stage. Furthermore, overexpression of IC53d promoted the proliferation, colony formation and $\mathrm{G}_{1} / \mathrm{S}$ phase transition of gastric cancer cells, leading to enhancement of tumorigenesis in vitro and in vivo. Overexpression of IC53d also promoted phosphorylation of protein kinase $\mathrm{B}(\mathrm{AKT})$ and glycogen synthase kinase $3 \beta$
\end{abstract}

Correspondence to: Dr Chao-Hui Zheng or Dr Chang-Ming Huang, Department of Gastric Surgery, Fujian Medical University Union Hospital, 29 Xinquan Road, Fuzhou, Fujian 350001, P.R. China E-mail: wwkzch@163.com

E-mail: hcmlr2002@163.com

*Contributed equally

Key words: gastric cancer, cyclin-dependent kinase 5 regulatory subunit-associated protein 3 isoform d, isoform, proliferation
(GSK3 3$)$, which increased the expression of cyclin D1. In addition, high cyclin D1 expression was associated with a significantly worse prognosis for patients compared with in patients with low cyclin D1 expression. These results indicated that IC53d may promote the phosphorylation of AKT and GSK3 $\beta$, which in turn may increase cyclin D1 expression, enhancing $G_{1} / S$ phase transition, accelerating cell cycle progression, promoting the proliferation of gastric cancer cells, and inducing a poor prognosis in patients with gastric cancer.

\section{Introduction}

Gastric cancer is a common malignancy that poses a risk to human health. Although complete surgical resection is considered the first choice for treating gastric cancer, the long-term survival rate following surgery is still not optimal $(1,2)$. To date, the etiology and pathogenesis of gastric cancer have not been fully elucidated, and the lack of specific and highly effective therapeutic drugs is an obstacle that restricts the prevention and treatment of gastric cancer $(3,4)$. In recent years, inhibiting cell cycle progression and proliferation have shown great potential for preventing and treating gastric cancer (5-7). Our future study on cell cycle regulatory proteins is expected to provide a novel target for the treatment of gastric cancer.

Cyclin-dependent kinase 5 (CDK5) regulatory subunitassociated protein 3 (CDK5RAP3 or C53) is a CDK5 that activates a binding protein that was first identified using the yeast two-hybrid system to be a binding protein of CDK5 activators p35 and p39 $(8,9)$. C53 regulates cell cycle progression, epidermal cell adhesion, and cell migration during early embryonic development (10). C53 is widely expressed in various tissues and cells throughout the body, including the heart, brain, skeletal muscle, placenta, lung, liver, kidney and pancreas (11). In the presen study, a C53 isoform d (IC53d) lentivirus was constructed, according to the National Center of Biotechnology Information (NCBI) (NCBI accession number: NP_001265127.1; https://www.ncbi. nlm.nih.gov/protein/NP_001265127.1). This gene is located 
on chromosome $17 \mathrm{q} 21.32$ and is $2,794 \mathrm{bp}$ in length. This gene contains 13 exons that encode a protein containing 316 amino acids, with a theoretical isoelectric point value of 4.75 and molecular mass of $35.3 \mathrm{kDa}$. Sequence alignment revealed that IC53d is a transcriptional variant of the C53 gene. Compared to variant 1 (the longest and most complete transcriptional mutant), this variant contains the penultimate exon, resulting in a new $3^{\prime}$ code area and shorter 3' untranslated region (data not shown).

In recent years, numerous studies have revealed that C53 serves different roles in various tumor types, and participates in several classic tumor signaling pathways (12-14). Therefore, it was hypothesized that the expression levels and functional differences of C53 in various tumor types are due to selective cleavage variants/isoforms of C53. However, at present, few studies have been conducted regarding this topic. The present study analyzed the expression of IC53d in gastric cancer and adjacent tissues, and assessed the role and mechanism of IC53d in vivo and in vitro. Notably, the presen study aimed to knockdown IC53d expression in gastric cancer cells with a lentivirus; however, since IC53d has homologous sequences with other C53 splice variants, stably infected cells in which IC53d was specifically knocked out could not be obtained (data not shown). Therefore, the presen study focused on the effects of IC53d overexpression on gastric cancer cells. In addition, the importance of cyclin D1 in the prognosis of patients with gastric cancer was assessed, with the aim of identifying a novel gene target for the diagnosis and treatment of gastric cancer.

\section{Materials and methods}

Human gastric tumor tissues. Gastric cancer specimens were collected between January 2013 and January 2018 at the Department of Gastric Surgery, Fujian Medical University Union Hospital (Fuzhou, China) from patients who underwent D2 lymph node dissection and gastrectomy for gastric cancer. The present study comprised 214 patients that were diagnosed with gastric cancer and did not receive adjuvant chemotherapy prior to surgery. All patients were diagnosed with gastric cancer, and had detailed clinical and pathological data. All histopathological sections of gastric cancer were confirmed by hematoxylin and eosin staining conducted by pathologists. Clinicopathological data available for the patients with gastric cancer included age, sex, primary tumor size, primary tumor location, differentiation, histological type, Borrman classification, depth of invasion, lymph node metastasis, distant metastasis, and tumor-node-metastasis (TNM) stage. TNM stage was classified according to the 2016 International Conference of The Union for Cancer TNM classification of gastric cancer (8th edition) (15). Collected tissue samples were immediately frozen in liquid nitrogen and stored at $-80^{\circ} \mathrm{C}$ until further analysis. Among them, 134 gastric cancer and adjacent non-cancerous tissues collected between January 2013 and January 2014 were fixed in 4\% paraformaldehyde at room temperature for 12-24 h and embedded in paraffin, and were used for immunohistochemical analysis. Between January 2017 and January 2018, 80 fresh gastric cancer tissues and adjacent non-cancerous tissues were collected for reverse transcription-quantitative polymerase chain reaction (RT-qPCR) analysis. Clinical and pathological data were retrospectively analyzed. The present study was approved by the Ethics Committee of Fujian Medical University Union Hospital, and written informed consent was obtained from patients.

Immunohistochemistry (IHC) and scoring. Paraffin-embedded sections containing sufficient formalin-fixed tumor tissues were continuously sectioned at a thickness of $4 \mu \mathrm{m}$ and were mounted on silane-coated slides for immunohistochemical analysis. The sections were deparaffinized with xylene and rehydrated in 95, 85 and $75 \%$ ethanol. Antigen retrieval was performed by subjecting the slides to high-pressure sterilization at $121^{\circ} \mathrm{C}$ for $2 \mathrm{~min}$ in $0.01 \mathrm{~mol} / 1$ sodium citrate buffer solution ( $\mathrm{pH}$ 6.0). Endogenous peroxidase activity was blocked by incubating the slides with $3 \% \mathrm{H}_{2} \mathrm{O}_{2}$ at room temperature for $10 \mathrm{~min}$. The sections were then washed in PBS solution and blocked in $10 \%$ goat serum (OriGene Technologies, Inc., Beijing, China) for $30 \mathrm{~min}$ at $37^{\circ} \mathrm{C}$. Subsequently, the sections were incubated with diluted rabbit anti-human cyclin D1 (cat. no. ab16663; 1:50 dilution; Abcam, Cambridge, UK), cleaved caspase-3 (cat. no. ab13847; 1:300 dilution; Abcam) and Ki67 (cat. no. ab15580; 1:50 dilution; Abcam) overnight in a humidified chamber at $4^{\circ} \mathrm{C}$. After three washes in PBS, the sections were incubated with a horseradish peroxidase-conjugated secondary antibody (10 $\mu$ l; cat. no. SAP-9100; Histostain $^{\mathrm{TM}}$-SAP Kit; OriGene Technologies, Inc.) at room temperature for $30 \mathrm{~min}$. The signal was developed with diaminobenzidine solution, followed by counterstaining with $20 \%$ hematoxylin. Finally, all slides were dehydrated and mounted on cover glass. For negative controls, the primary antibody was replaced with non-specific antibody (cat. no. P0103; Beyotime Institute of Biotechnology, Haimen, China) diluent.

IHC-stained tissue sections were reviewed by two experienced pathologists using a microscope (IX-10; Olympus Corporation, Tokyo, Japan) and independently scored based on the proportion of stained cells and the intensity of staining. The standard for the evaluation of cyclin D1 and Ki67 staining intensity was as follows: No staining, 0; weak staining, 1 ; moderate staining, 2; strong staining, 3 . The positive proportion of stained tumor cells was scored as follows: $\leq 5 \%$ positive cells, $0 ; 6-25 \%$ positive cells, $1 ; 26-50 \%$ positive cells, $2 ; \geq 51 \%$ positive cells, 3 . If the total score (percentage score $\mathrm{x}$ intensity score) was $<3$, the protein expression was considered low, whereas if the score was $\geq 4$, the protein expression was considered high.

Cell culture and construction of stable cell lines. Five gastric cancer cell lines (MKN74, AGS, MGC-803, SGC-7901 and HGC-27) were purchased from the Institute of Biochemistry and Cell Biology, Chinese Academy of Sciences (Shanghai, China). MKN74, MGC-803, SGC-7901 and HGC-27 cells were cultured in RPMI-1640 (Gibco; Thermo Fisher Scientific, Inc., Waltham, MA, USA), and AGS cells were cultured in Dulbecco's modified Eagle's medium/F12 Gibco; Thermo Fisher Scientific, Inc.), both supplemented with $10 \%$ fetal bovine serum (FBS; Gibco; Thermo Fisher Scientific, Inc.) in an atmosphere containing $5 \% \mathrm{CO}_{2}$ at $37^{\circ} \mathrm{C}$.

A lentivirus (Shanghai GeneChem Co., Ltd., Shanghai, China) was used to construct a cell line overexpressing IC53d (NP_001265127.1; Lenti-IC53d) and a corresponding empty 
vector [Lenti-negative control (NC)]. A total of 1 day prior to lentiviral infection, AGS and MGC- 803 cells were seeded in 6 -well plates at $5 \times 10^{4}$ cells/well (20-30\% confluence). Lenti-IC53d was transfected into cells using polyphenylene $(10 \mathrm{mg} / \mathrm{ml})$ and an intensified infection solution (Hitrans G virus infective enhancer; Shanghai GeneChem Co., Ltd.) under appropriate conditions (multiplicity of infection=10). Using the same method for Lenti-IC53d, the corresponding Lenti-NC was introduced into cells and incubated at $37^{\circ} \mathrm{C}$ in an incubator containing $5 \% \mathrm{CO}_{2}$ for $6-8 \mathrm{~h}$; subsequently, fresh medium was added to the cells. To establish a stable cell line, cells were selected after $48 \mathrm{~h}$ in fresh medium by replacing the medium with medium containing puromycin $(1-2 \mathrm{mg} / \mathrm{ml}$; Sigma-Aldrich; Merck KGaA, Darmstadt, Germany); the cells were cultured with puromycin for at least 1 week after infection, and cells were used for mRNA and protein analyses, and other tests.

Total RNA extraction and RT-qPCR. Total RNA was extracted from cell lines and tissue samples using TRIzol ${ }^{\circledR}$ reagent (Invitrogen; Thermo Fisher Scientific, Inc.). First-strand cDNA was synthesized with PrimeScript RT Master Mix (Takara Biotechnology, Ltd., Dalian, China), according to the manufacturer's protocol. After RT of total RNA, qPCR was conducted to examine the expression levels of IC53d using SYBR-Green PCR Master Mix (Takara Biotechnology, Ltd.) on a Bio-Rad Real-Time PCR instrument (Bio-Rad Laboratories, Inc., Hercules, CA, USA). Thermocycling conditions were as follows: Denaturation, $94^{\circ} \mathrm{C}$ for $5 \mathrm{~min}$; followed by 40 cycles at $94^{\circ} \mathrm{C}$ for $30 \mathrm{sec}, 55^{\circ} \mathrm{C}$ for $30 \mathrm{sec}$ and $72^{\circ} \mathrm{C}$ for $60 \mathrm{sec}$; and a final elongation step at $72^{\circ} \mathrm{C}$ for $7 \mathrm{~min}$. GAPDH was used as an internal reference gene to normalize the mRNA levels between different samples for an exact comparison of transcription levels. The primer sequences were as follows (5'-3'): GAPDH, forward GGGAGCCAAAAGGGT CAT, reverse GAGTCCTTCCACGATACCAA; and IC53d, forward AGGCTGACTGGAAGATGGAA and reverse AGA AGGAGAATCTGTGGTTTTCG. To confirm that the primers were correct, Southern blotting was conducted as follows: PCR products from three randomly selected patient samples (10 ng) were subjected to $1 \%$ agarose electrophoresis at $200 \mathrm{~V}$ for $60 \mathrm{~min}$, after which, the gel was stained with ethidium bromide (UltraPure Ethidium Bromide; cat. no. 15585011; Thermo Fisher Scientific, Inc.). The results confirmed that the primers were correct (Fig. 1A). Data were analyzed using the $2^{-\Delta \Delta \mathrm{Cq}}$ method (16) with GAPDH as the constitutive marker.

Cell proliferation assay. Gastric cancer cells were seeded into a 96-well plate at 1,000 cells/well (100 $\mu \mathrm{l}$ cell suspension). Subsequently, $100 \mu 1$ serum-free medium containing 10\% Cell Counting Kit-8 (CCK-8; cat. no. HY-K0301; MedChemExpress, Monmouth Junction, NJ, USA) reagent was added on days 0,1,2 and 3. Optical density was measured at $450 \mathrm{~nm}$ after $2 \mathrm{~h}$, and a multiplication curve was generated. Five duplicate wells were used for each cell line, and the assay was repeated three times.

Cell counting assays. The cells were routinely digested every $24 \mathrm{~h}$; briefly, the cells were washed with 1X PBS and digested in $1 \mathrm{ml}$ Trypsin-EDTA (0.25\%), phenol red (cat. no. 25200056;
Gibco; Thermo Fisher Scientific, Inc.) for $1 \mathrm{~min}$ at $37^{\circ} \mathrm{C}$. Digestion was terminated using $1 \mathrm{ml}$ corresponding medium; subsequently, the cells were centrifuged at $240 \mathrm{x}$ g for $5 \mathrm{~min}$, the supernatant was discarded and $1 \mathrm{ml}$ medium was aspirated to prepare a cell suspension. Subsequently, a 20- $\mu$ l cell suspension was added to an automated cell counter (ALIT Life Science Co., Ltd., Shanghai China), which was placed under a Countstar ${ }^{\circledR}$ BioTech (Countstar; ALIT Life Science Co., Ltd.). Cells were counted in three different fields and the mean was calculated.

Colony formation assay. Gastric cancer cells in the logarithmic growth phase were inoculated into a 6-well plate at 1,000 cells/well, cultured for 10 days, washed three times with 1X PBS, soaked in $70 \%$ methanol for $15 \mathrm{~min}$, and stained with crystal violet for $15 \mathrm{~min}$. After washing three times with PBS, ensuring no cells were lost, the number of colonies was counted under an optical light microscope (IX-70; Olympus Corporation); each assay was repeated three times.

Cell invasion and migration assay. For the cell invasion assay,

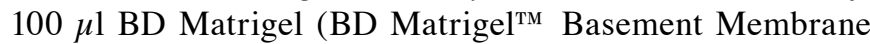
Matrix; cat. no. 354234; BD Biosciences, Franklin Lakes, NJ, USA) was added to the upper chamber of a Transwell system and incubated for $15 \mathrm{~min}$ at $37^{\circ} \mathrm{C}$. Subsequently, for the cell invasion and migration assays, a total of $2 \times 10^{4}$ cells $(100 \mu \mathrm{l}$ cell suspension) were placed into the upper chamber of a Transwell system (polycarbonate filters, $8-\mu \mathrm{m}$ pore size; BD Biosciences), and $500 \mu \mathrm{l}$ culture medium containing $10 \%$ FBS was added to the lower chamber. After a routine culture for 16-24 h, the cells on the matrix and upper chamber were removed with a cotton swab. Migratory/invasive cells were counted under a light microscope (IX-70; Olympus Corporation) following crystal violet staining.

Flow cytometry. Apoptosis was detected using an Annexin Vfluorescein isothiocyanate (FITC) apoptosis kit (Nanjing Keygen Biotech Co., Ltd., China), according to the manufacturer's protocol. Cells were maintained under stress conditions at $37^{\circ} \mathrm{C}$ for $24 \mathrm{~h}$ (glucose and amino acid starvation) prior to measuring the rate of apoptosis. Briefly, cells were collected and stained with Annexin V-FITC and propidium iodide (PI) (1 $\mu \mathrm{l}$ Annexin V-FITC and PI in $100 \mathrm{ml}$ cell suspension) for $15 \mathrm{~min}$ at room temperature, and the cell apoptotic rate was measured by flow cytometry (BD FACSVerse 4 color Flow Cytometer; BD Biosciences).

For cell cycle analysis, cells were maintained in serum-free medium for $24 \mathrm{~h}$, after which, they were collected and fixed with $70 \%$ ethanol overnight at $4^{\circ} \mathrm{C}$. Subsequently, cells were washed three times with $1 \mathrm{X}$ PBS, stained with PI (1 $\mu 1 \mathrm{PI}$ in $100 \mathrm{ml}$ cell suspension) for $15 \mathrm{~min}$ at room temperature and the cell cycle progression was measured by flow cytometry (BD FACSVerse 4 color Flow Cytometer; BD Biosciences).

Protein extraction and western blot analysis. When cells reached $80-90 \%$ confluence, they were washed twice with pre-cooled PBS and proteins were extracted with radioimmunoprecipitation assay lysis buffer (Thermo Fisher Scientific, Inc.) containing $10 \%$ phosphatase inhibitor cocktail (Roche Diagnostics, Indianapolis, IN, USA). In addition, 
proteins were extracted from frozen gastric cancer tissues and non-tumor tissues using a Whole Protein Extraction kit (Fermentas; Thermo Fisher Scientific, Inc., Pittsburgh, PA, USA), according to the manufacturer's protocol. Protein concentration was determined using the bicinchoninic acid method. Protein samples ( $40 \mu \mathrm{g} /$ lane) were separated by $10 \%$ SDS-PAGE and transferred to polyvinylidene fluoride (PVDF) membranes. Subsequently, at $37^{\circ} \mathrm{C}, 5 \%$ skim milk was used to block the PVDF membranes for $1 \mathrm{~h}$. The membranes were then incubated at $4^{\circ} \mathrm{C}$ overnight with the following primary antibodies: Anti-cyclin D1 $(1: 1,000$; cat. no. ab16663), anti-hemagglutinin (HA; 1:1,000; cat. no. ab18181) and anti-GAPDH (1:2,000; cat. no. ab181602; Abcam); anti-phosphorylated (P)-protein kinase B (AKT; S473; 1:1,000, cat. no. 4060), anti-AKT (1:1,000; cat. no. 4685), anti-P-glycogen synthase kinase $3 \beta$ (GSK3 $\beta$; S9; 1:1,000, cat. no. 9323) and anti-GSK3 $\beta$ (1:1,000, cat. no. 12456; Cell Signaling Technology, Inc., Danvers, MA, USA) and washed three times with Tris-buffered saline-0.05\% Tween-20 (TBS-T) (5 min/wash). Subsequently, membranes were incubated at room temperature with horseradish peroxidase-conjugated secondary antibodies [Goat Anti-Rabbit immunoglobulin (Ig) $\mathrm{G}(\mathrm{H}+\mathrm{L})$ and Goat Anti-Mouse $\operatorname{IgG}(\mathrm{H}+\mathrm{L})$ Secondary Antibody (1:1,000 dilutions; HRP Conjugate; cat. nos. BA1056 and BA1038; Boster Biological Technology, Pleasanton, CA, USA) for $1 \mathrm{~h}$. GAPDH was used as an internal control. Finally, the membranes were washed with TBS-T for $30 \mathrm{~min}$ and protein bands were detected using enhanced chemiluminescence (GE Healthcare, Chicago, IL, USA). ImageJ (v2.1.4.7; National Institutes of Health, Bethesda, MD, USA) was used to measure the gray values of protein bands for semi-quantitative analysis.

In addition, gastric cancer cells were treated with $50 \mu \mathrm{M}$ LY294002 (cat. no. 9901; Cell Signaling Technology, Inc.) for $24 \mathrm{~h}$ at $37^{\circ} \mathrm{C}$ in an incubator containing $5 \% \mathrm{CO}_{2}$. Subsequently, proteins were extracted as aforementioned.

Tumor xenograft transplantation assay. Male BALB/c nude mice (age, 4-5 weeks; weight, 14-16 g; Institute of Zoology, Chinese Academy of Sciences) were randomly divided into two groups: Negative control (NC) and IC53d groups ( $\mathrm{n=5/group).}$ The mice were maintained in a specific pathogen-free environment (free access to food/water; 10-h light and 14-h dark cycle; temperature, $18-29^{\circ} \mathrm{C}$; daily temperature difference, $\leq 3^{\circ} \mathrm{C}$; relative humidity, 40-70\%; fresh air ventilation, 10 times/h; air flow rate, $\leq 0.18 \mathrm{~m} / \mathrm{sec}$; pressure difference, $25 \mathrm{~Pa}$; cleanliness, the environment was cleaned once a week; ammonia concentration, $15 \mathrm{mg} / \mathrm{m}^{3}$; noise, $\leq 60 \mathrm{~dB}$; illuminance, 150-300 Lux.). All animal procedures were performed according to the Animal Protection Committee of Fujian Medical University (Fuzhou, China), and the animal study was approved by the Ethics Committee of Fujian Medical University/Laboratory Animal Center (Fuzhou, China). Stable MGC-803 cells with high IC53d expression and corresponding control cells $\left(3 \times 10^{6}\right)$ were suspended in $200 \mu \mathrm{l}$ PBS and subcutaneously injected into the right axillary fossa of nude mice. The tumor volume was measured every 7 days, as follows: Tumor volume $=\left(\right.$ length $\mathrm{x}$ width $\left.{ }^{2}\right) / 2 \mathrm{~cm}^{2}$. The mice were sacrificed by cervical dislocation on the 35 th day post-injection and tumor weight was measured.
Immunofluorescence. For immunofluorescence, sections were prepared in the same manner as for IHC, until primary antibody incubation. Subsequently, after overnight incubation with an anti-cyclin D1 antibody (1:200; cat. no. ab16663; Abcam) in a humidified chamber at $4^{\circ} \mathrm{C}$, PBS washing was performed three times, and fluorescein-labeled secondary antibodies [sheep anti-rabbit IgG H\&L (FITC); 1:1,000, cat. no. ab6791; Abcam] were added and incubated at room temperature for $1 \mathrm{~h}$ in the dark. PBS was used to wash sections in the dark three times. DAPI staining solution was then added drop-wise, and coverslips were mounted onto a glass slide (Santa Cruz Biotechnology, Inc., Dallas, TX, USA), which was incubated at room temperature for $1 \mathrm{~min}$ in the dark. Images were captured with a confocal microscope (IX-70; Olympus Corporation).

Patient follow-up. All patients were followed up once every 3 months for the first 2 years, and were then followed up every 6 months for the next 3-5 years. The last follow-up time point was December 2017. Follow-up routine examinations, including a physical examination, laboratory tests (CA19-9, carcinoembryonic antigen and CA72-4), chest X-ray, abdominal computed tomography, B-scan ultrasonography and gastroscopy were performed each year. The total survival time was defined as the time from surgery to the last follow-up, time of death, or expiration of the follow-up (e.g., lost to follow-up, death from other diseases, etc.).

Statistical analysis. All experiments were repeated three times and measurement data are presented as the means \pm standard deviation. All data were processed by SPSS 23.0 statistical software package (SPSS, Inc., Chicago, IL, USA) and Prism 7.0 software (GraphPad Software, Inc., La Jolla, CA, USA). Categorical variables were analyzed using the $\chi^{2}$ test or Fisher's exact test, whereas continuous variables were analyzed using Student's t-test. Multiple comparisons between groups were determined using one-way analysis of variance and a Bonferroni multiple comparisons test. Independent samples t-test was performed to analyze differences in RT-qPCR data between NC and IC53d cells, and between normal and tumor tissues, cell invasion data, apoptosis data and flow cytometry data. Growth curves (CCK-8 data and cell count data) were analyzed using an independent t-test. Univariate survival analysis was performed using the Kaplan-Meier method, and the curves were compared using the log-rank test. Multivariate analysis was performed using the Cox proportional hazards model to further evaluate all significant prognostic factors determined in the univariate analysis. $\mathrm{P}<0.05$ was considered to indicate a statistically significant difference.

\section{Results}

Upregulation of IC53d in human gastric cancer. The present study detected the expression levels of IC53d in 80 cases of gastric cancer and adjacent tissues using RT-qPCR (Fig. 1B and C). According to a previous study (17), when the expression levels of IC53d were higher in gastric cancer tissues than in the corresponding adjacent tissues ( $\geq 1$-fold change), this group was termed the upregulation group (57 cases, 71.3\%). Conversely, when the expression levels of IC53d were lower in gastric cancer tissues than in the 

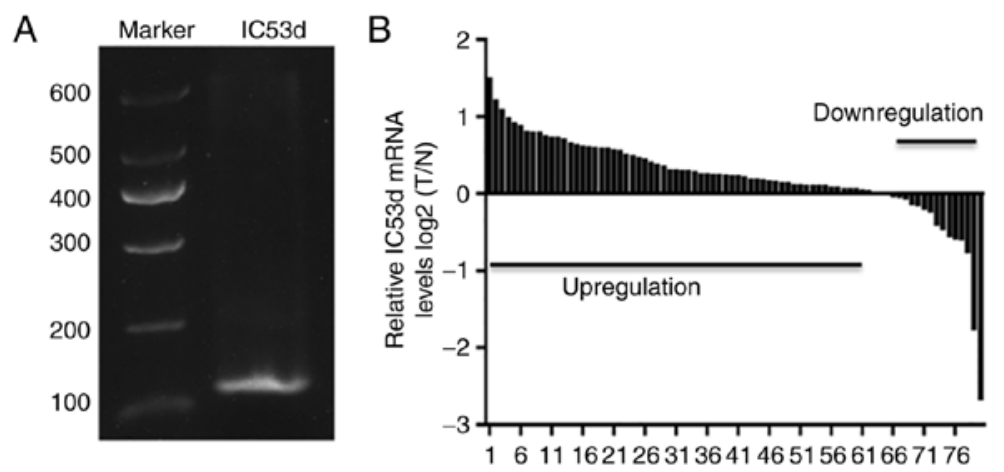

C

D

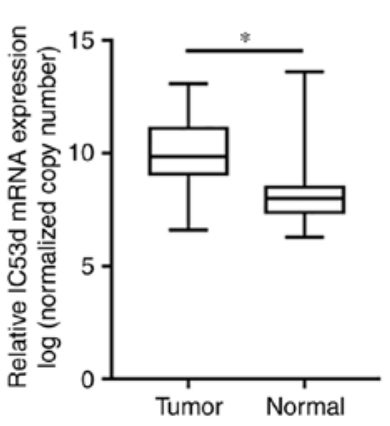

$\mathrm{F}$

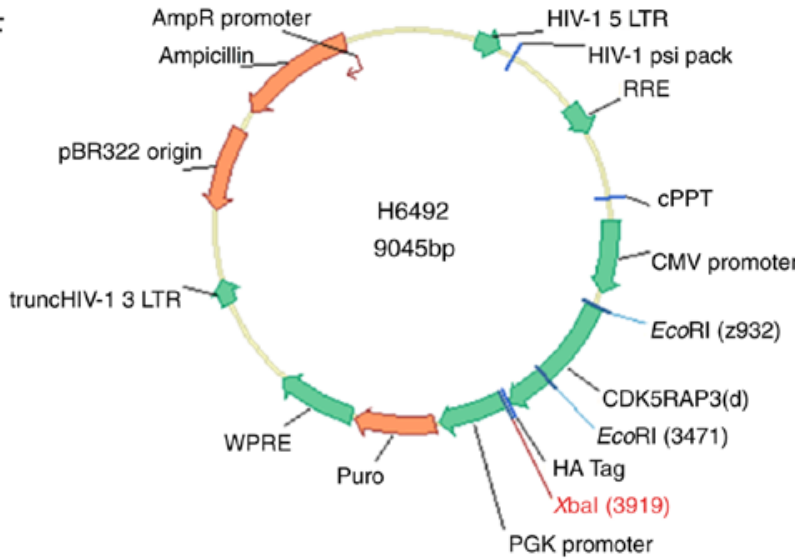

E

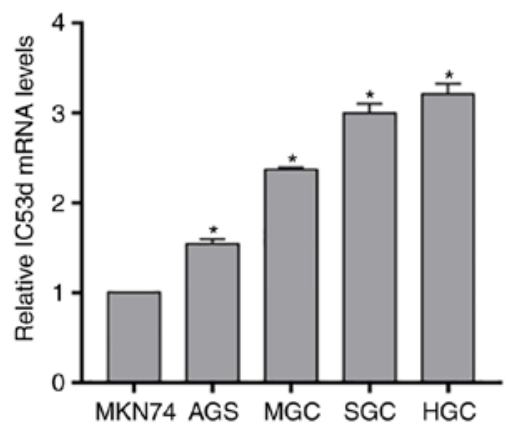

G

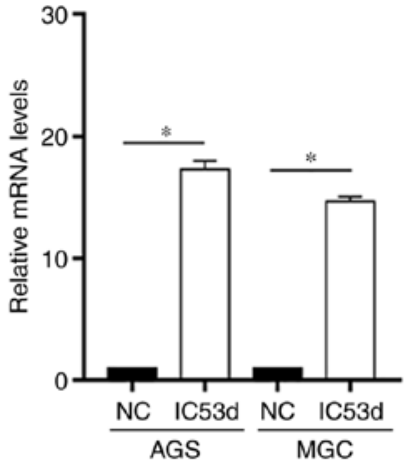

$\mathrm{H}$

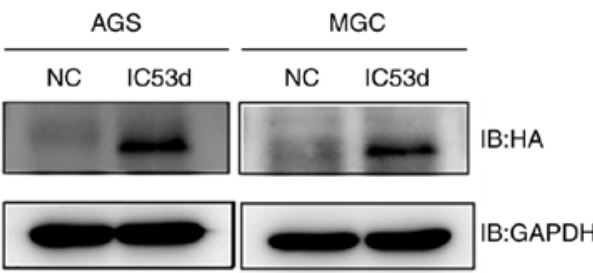

Figure 1. Expression levels of IC53d in gastric cancer tissues and in stably infected cells. (A) IC53d primers were validated by Southern blotting. (B) mRNA expression levels of IC53d in gastric cancer and respective adjacent non-tumor tissues were measured by RT-qPCR. The ratios of IC53d in gastric tumor compared to respective non-tumor tissues (T/N) from 80 patients are presented. (C) Reduction ratio average of IC53d mRNA levels in T/N. (D) IC53d expression scores represented as box plots; horizontal lines represent the median, the bottom and top of the boxes represent the 25th and 75th percentiles, respectively, and the vertical bars represent the range of data. IC53d expression in gastric tumor tissues and respective adjacent non-tumor tissues was compared using t-test, $n=80 .{ }^{*} \mathrm{P}<0.05$. (E) RT-qPCR analysis of the expression levels of IC53d in various gastric cancer cell lines (MKN74, AGS, MGC-803, SGC-7901 and HGC-27). Results are presented as the means \pm standard deviation, $n=3$. ${ }^{*} \mathrm{P}<0.05$ vs. MKN74 cells. (F) 3FLAG open-reading frame of the Lenti-CMV-MCS-3FLAG-PGK-Puro plasmid was replaced with cDNA. (G) Overexpression efficiency in AGS and MGC-803 cells infected with the IC53d plasmid. Results are presented as the means \pm standard deviation, $n=3$. "P<0.05 vs. NC group. (H) Cell lysates were extracted from AGS and MGC cell lines stably expressing HA-tagged proteins (HA-tagged IC53d plasmid). HA and GAPDH was detected by western blotting. HA, hemagglutinin; IB, immunoblotting; IC53d, cyclin-dependent kinase 5 regulatory subunit-associated protein 3 isoform d; NC, negative control; RT-qPCR, reverse transcription-quantitative polymerase chain reaction.

corresponding adjacent tissues, this group was defined as the downregulation group (23 cases, $28.7 \%$; Table I). The results of a univariate analysis revealed that the mRNA expression levels of IC53d were upregulated in patients with T2 and T3 stage cancer (Table I). The results revealed that IC53d expression was significantly increased in gastric cancer tissues compared 
Table I. Association between clinicopathological characteristics and IC53d expression in patients with gastric cancer.

\begin{tabular}{|c|c|c|c|c|}
\hline \multirow[b]{2}{*}{ Characteristic } & \multicolumn{2}{|c|}{ IC53d expression } & \multirow[b]{2}{*}{$\chi^{2}$} & \multirow[b]{2}{*}{ P-value } \\
\hline & Low $(n=23)$ & High $(n=57)$ & & \\
\hline Sex & & & 0.573 & 0.449 \\
\hline Male & 15 & 42 & & \\
\hline Female & 8 & 15 & & \\
\hline Age (years) & & & 0.214 & 0.644 \\
\hline$>60$ & 15 & 34 & & \\
\hline$\leq 60$ & 8 & 23 & & \\
\hline Tumor size $(\mathrm{cm})$ & & & 1.898 & 0.168 \\
\hline$>5$ & 9 & 32 & & \\
\hline$\leq 5$ & 14 & 25 & & \\
\hline Degree of differentiation & & & 1.020 & 0.313 \\
\hline Well/moderate & 10 & 18 & & \\
\hline Poor/not differentiated & 13 & 39 & & \\
\hline Depth of invasion & & & 7.962 & 0.047 \\
\hline $\mathrm{T} 1$ & 4 & 1 & & \\
\hline $\mathrm{T} 2$ & 12 & 29 & & \\
\hline $\mathrm{T} 3$ & 7 & 25 & & \\
\hline $\mathrm{T} 4$ & 0 & 2 & & \\
\hline Lymph node metastasis & & & 5.250 & 0.154 \\
\hline N0 & 8 & 8 & & \\
\hline $\mathrm{N} 1$ & 9 & 26 & & \\
\hline $\mathrm{N} 2$ & 3 & 7 & & \\
\hline N3 & 3 & 16 & & \\
\hline Distant metastasis & & & 0.828 & 0.363 \\
\hline Negative & 23 & 55 & & \\
\hline Positive & 0 & 2 & & \\
\hline TNM stage & & & 6.001 & 0.112 \\
\hline I & 8 & 7 & & \\
\hline II & 7 & 19 & & \\
\hline III & 5 & 16 & & \\
\hline IV & 3 & 15 & & \\
\hline
\end{tabular}

IC53d, cyclin-dependent kinase 5 regulatory subunit-associated protein 3 isoform d; TNM, tumor-node-metastasis.

with in tumor-adjacent tissues (Fig. 1D), which suggested that IC53d may be a cancer-promoting gene in gastric cancer.

Stable overexpression of IC53d in gastric cancer cell lines. To further investigate the effects of IC53d on the tumorigenicity of gastric cancer, RT-qPCR was used to detect the expression levels of IC53d in different gastric cancer cell lines (MKN74, AGS, MGC-803, SGC-7901 and HGC-27) (Fig. 1E). The results revealed that IC53d exhibited low expression in AGS and MGC-803 cells. Therefore, AGS and MGC-803 cells were used as models, and were infected with a lentivirus constructed with an overexpression plasmid (Fig. 1F). The results of RT-qPCR confirmed that the mRNA expression levels of IC53d were upregulated (Fig. 1G). Western blot analysis of HA, which was tagged to the plasmid, also confirmed the upregulation of IC53d expression in the stably infected cell lines (Fig. 1H).

Overexpression of IC53d promotes proliferation of gastric cancer cells in vitro. The present study revealed that lentivirus-mediated upregulation of the IC53d gene promoted the proliferation of AGS and MGC-803 cells. Compared with in the $\mathrm{NC}$ group, the proliferation of gastric cancer cells was significantly increased in response to IC53d overexpression, as determined using the CCK-8 assay (Fig. 2A and B). Consistent with the aforementioned results, the proliferative ability (colony formation and cell counting assays) of gastric cancer cell lines was significantly higher in response to IC53d overexpression compared with in the NC group (Fig. 2C-E). Conversely, there was no significant difference in the invasive and migratory 
A

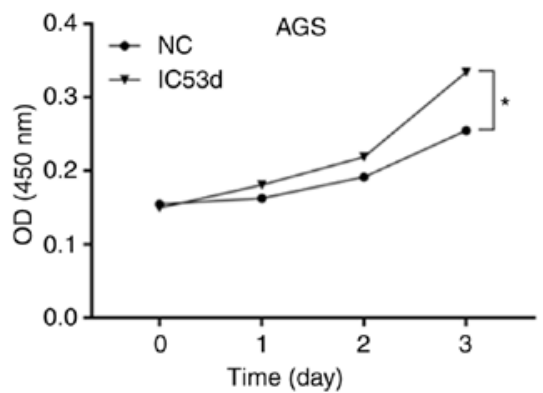

C

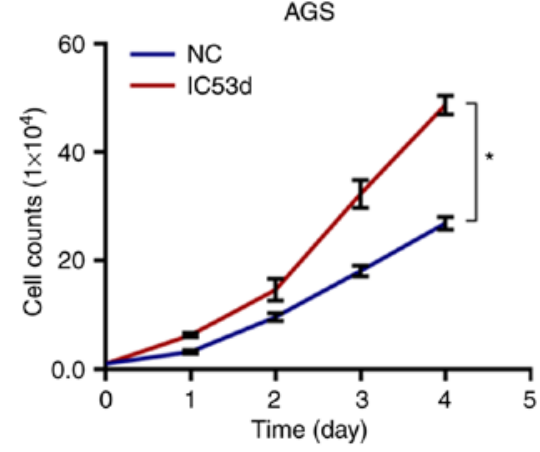

B

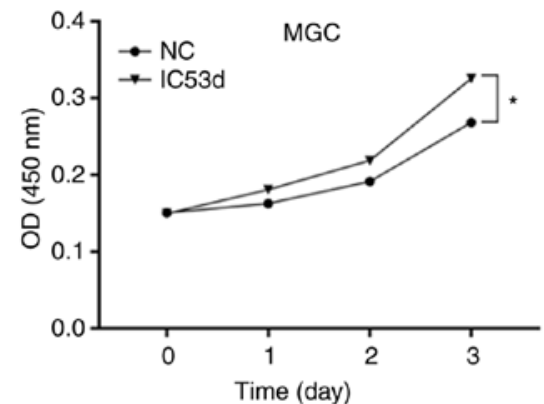

D

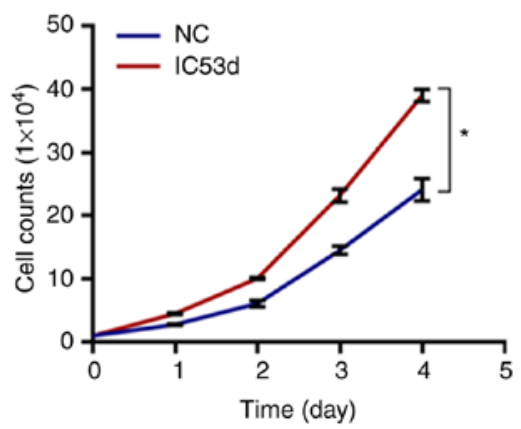

E
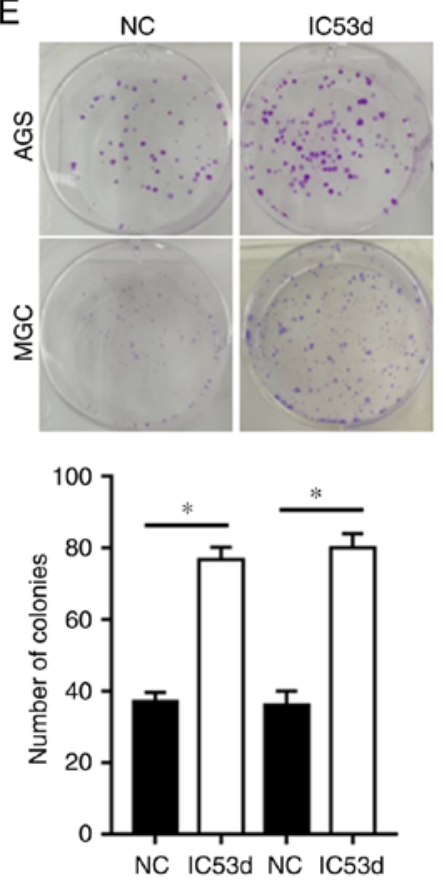

$\mathrm{F}$ F

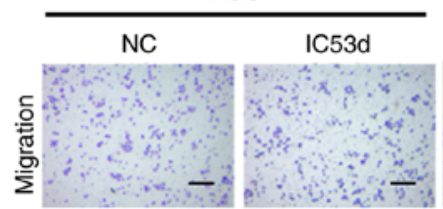

\begin{tabular}{ll} 
MGC \\
\hline NC $\quad$ IC53d
\end{tabular}
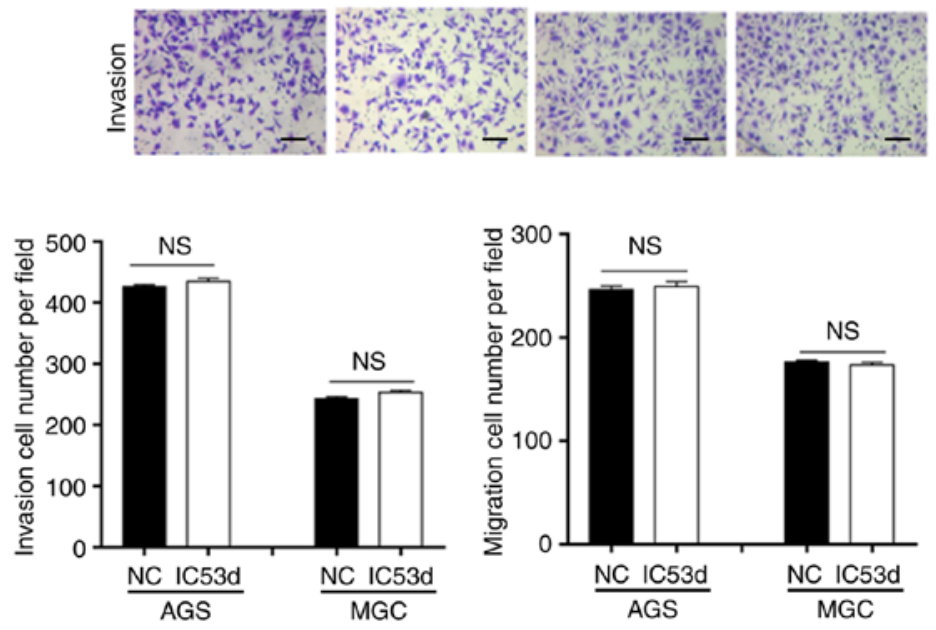

Figure 2. Cell function assays were used to verify the function of stably infected cells. (A and B) Proliferation of AGS and MGC-803 cells stably overexpressing IC53d over 3 days, as determined using the Cell Counting kit- 8 proliferation assay. ${ }^{*} \mathrm{P}<0.05$. (C and D) Cell counting assay of stable cells was conducted. ${ }^{*} \mathrm{P}<0.05$. These experiments were repeated three times. (E) Colony formation assay of stable cells was performed. Representative images are shown and results were quantified. ${ }^{*} \mathrm{P}<0.05$. These experiments were repeated three times. (F) Stable cells underwent Transwell assays. Representative images are shown (scale bar, $50 \mu \mathrm{m}$ ) and quantified results are presented as the means \pm standard deviation. ns, no significance. These experiments were repeated three times. IC53d, cyclin-dependent kinase 5 regulatory subunit-associated protein 3 isoform d; NC, negative control; OD, optical density.

abilities (Fig. 2F) of the cells, thus suggesting that IC53d may affect tumorigenicity by affecting the proliferative ability of gastric cancer cells.

IC53d promotes $G_{I} / S$ phase transition of gastric cancer cells through the AKT/GSK3 $\beta /$ cyclin D1 signaling pathway. To investigate the mechanism underlying the effects of IC53d on gastric cancer cell proliferation, flow cytometry was conducted to detect the apoptotic rate and cell cycle progression. The results of the apoptosis analysis revealed that there was no significant difference in the apoptotic rate between the IC53d overexpression group and the NC group (Fig. 3A and B). The results of the cell cycle analysis demonstrated that the number of S phase cells in the IC53d overexpression group was significantly higher compared with in the NC group (Fig. 3C), thus suggesting that IC53d may promote $\mathrm{G}_{1} / \mathrm{S}$ phase transition in gastric cancer cells. Subsequently, the present study examined the effects of IC53d on the expression of key proteins associated 

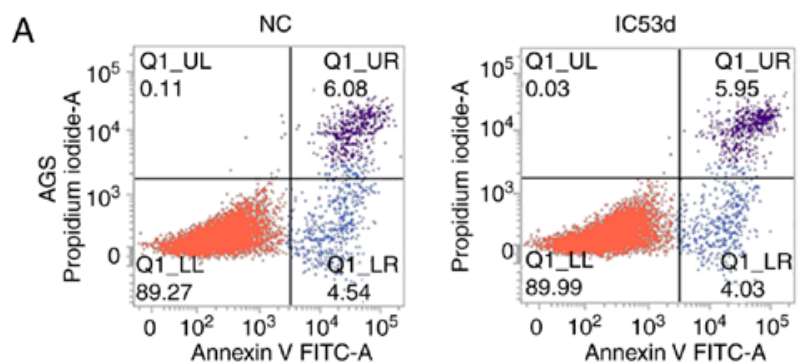

B
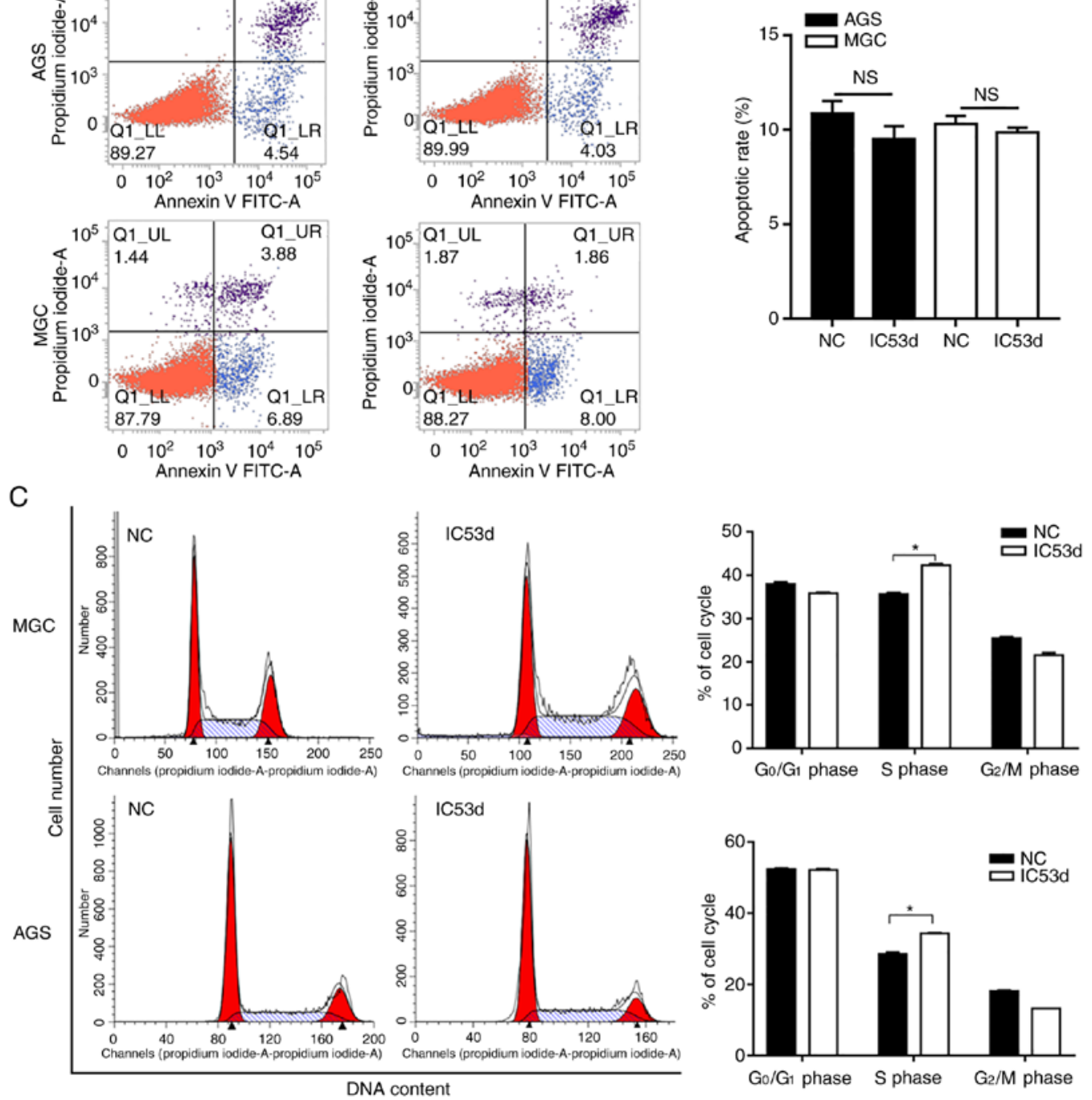

Figure 3. Flow cytometric analysis was used to determine the apoptotic rates and cell cycle progression of stably infected cells. (A and B) Flow cytometric analysis of the apoptotic rates in AGS and MGC-803 cells treated under stress conditions (glucose and amino acid starvation). Cells stably overexpressing IC53d and NC cells were compared. Results are presented as the means \pm standard deviation. ns, no significance. (C) Flow cytometric analysis of cell cycle progression in AGS and MGC cells after $24 \mathrm{~h}$ of serum starvation. Cells stably overexpressing IC53d and NC cells were compared. Representative images are shown and quantified results are presented as the means \pm standard deviation. ${ }^{*} \mathrm{P}<0.05$. IC53d, cyclin-dependent kinase 5 regulatory subunit-associated protein 3 isoform d; FITC, fluorescein isothiocyanate; NC, negative control.

with the $\mathrm{G}_{1} / \mathrm{S}$ phase transition of the cell cycle. Western blot analysis revealed that overexpression of IC53d promoted the phosphorylation of AKT and GSK3 $\beta$, and the expression of cyclin D1 (Fig. 4A and B). In addition, AKT was inhibited using LY294002. LY294002 blocked the effect of IC53d on cell proliferation and p-AKT levels (Fig. 4C and D), which further verified that IC53d may affect the phosphorylation levels of AKT in gastric cancer cells. When IC53d was overexpressed, the phosphorylation of AKT and the proliferation of cells were increased; however, when AKT was inhibited by LY294002, the phosphorylation of AKT and the proliferation of cells was not significantly different compared with in the NC group. These results indicated that IC53d increased the proliferation of cells by increasing the phosphorylation levels of AKT in gastric cancer. These results suggested that IC53d may increase the expression of cyclin D1 by promoting phosphorylation of AKT and GSK $3 \beta$, leading to $\mathrm{G}_{1} / \mathrm{S}$ phase transition and accelerating progression of the cell cycle, thereby promoting the proliferation of gastric cancer cells and progression of gastric cancer.

Overexpression of IC53d promotes tumor growth in vivo. To further determine the effects of IC53d on tumor growth, a subcutaneous tumor model of gastric cancer was generated using MGC-803 gastric cancer cells stably overexpressing IC53d. The tumor size and weight of the IC53d overexpression group were significantly greater than those of the $\mathrm{NC}$ group (Fig. 5A-C). Subsequently, proteins were extracted from subcutaneous tumor tissues for western blot analysis. The protein expression levels of cyclin D1 were higher in the IC53d overexpression group compared with in the NC group (Fig. 5D). In addition, immunofluorescence was used to detect the localization and expression of cyclin D1 in subcutaneous tumor tissues (Fig. 5E). IHC was also used to 
A

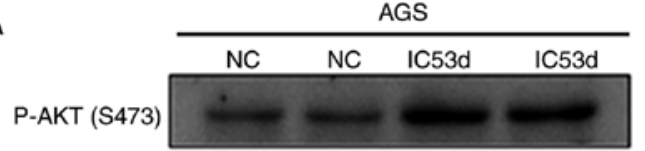

AKT

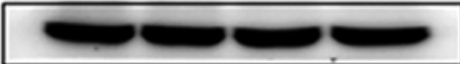

P-GSK3 (S9)

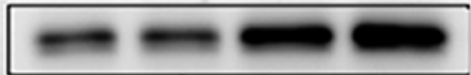

GSK3 $\beta$

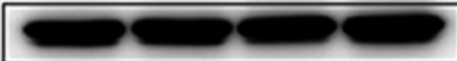

CyclinD1

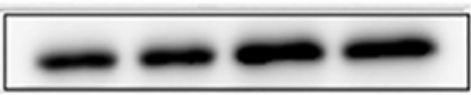

GAPDH

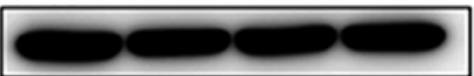

MGC
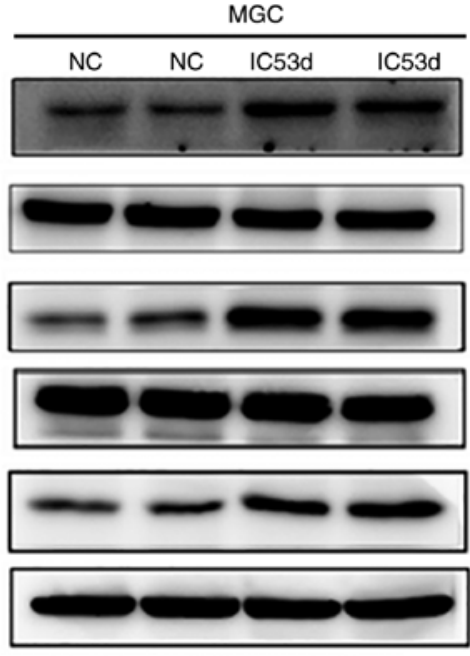

B
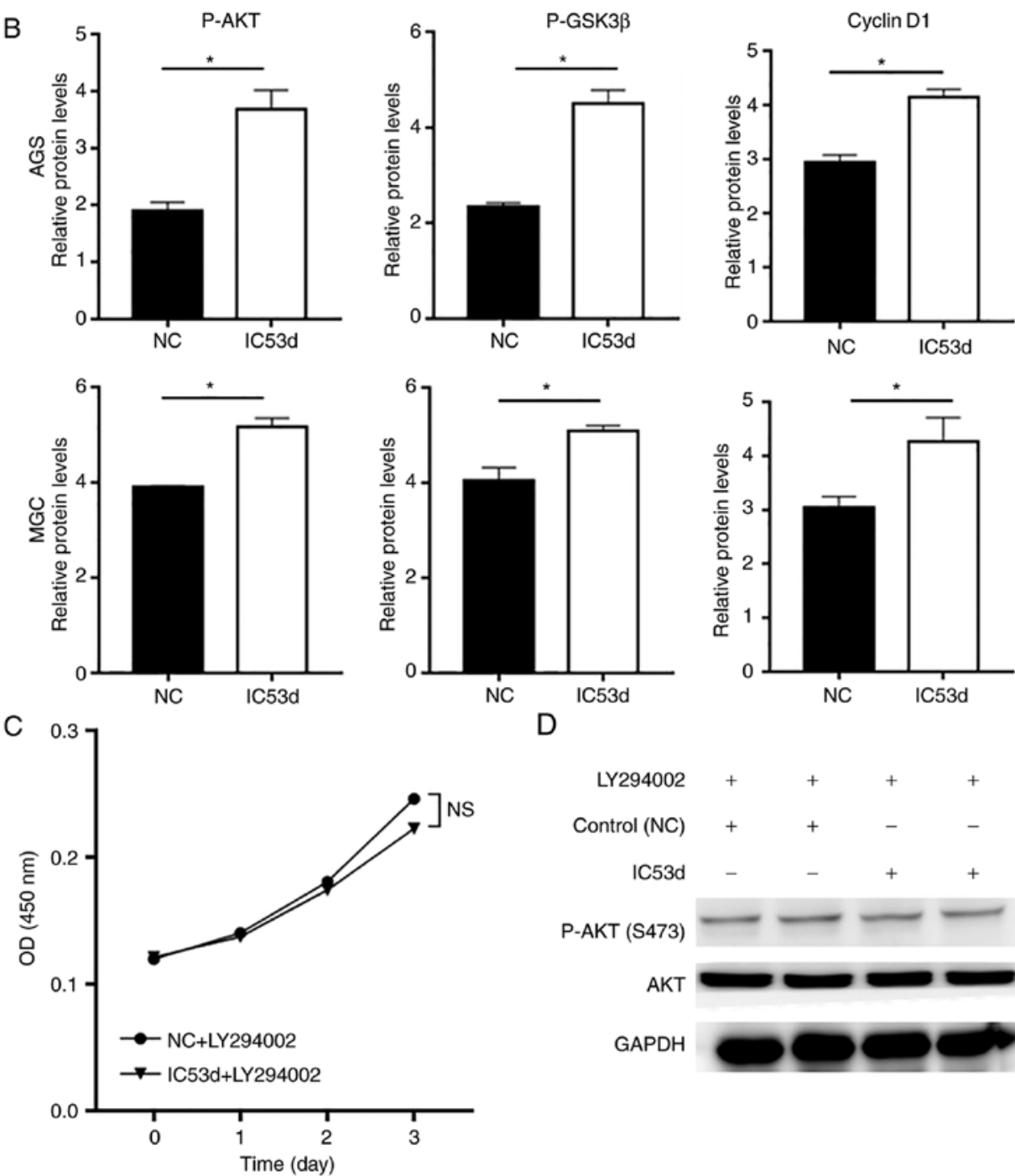

$\mathrm{D}$

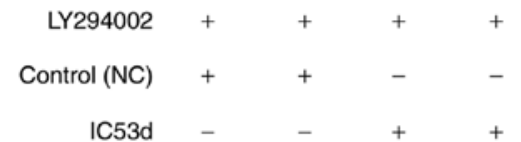

P-AKT (S473)

AKT

GAPDH

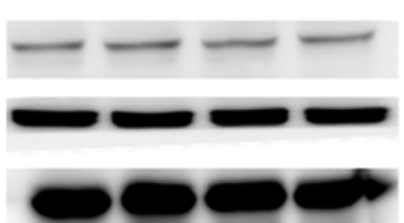

Figure 4. IC53d overexpression promotes transition of the $\mathrm{G}_{1} / \mathrm{S}$ phase. (A) Expression levels of $\mathrm{G}_{1} / \mathrm{S}$ phase transition-associated proteins (AKT, GSK3 $\beta$ and cyclin D1) in NC cells and cells overexpressing IC53d, as determined by western blotting. (B) Results were semi-quantified and are presented as the means \pm standard deviation. ${ }^{*} \mathrm{P}<0.05$. (C) LY294002 reversed the cell proliferation induced by IC53d overexpression. ns, no significance. (D) Inhibiting the phosphorylation of AKT using LY294002 blocked the effects of IC53d on cell proliferation and P-AKT expression; these findings further verified that IC53d affects the phosphorylation levels of AKT in gastric cancer cells. AKT, protein kinase B; GSK3 $\beta$, glycogen synthase kinase $3 \beta$; IC53d, cyclin-dependent kinase 5 regulatory subunit-associated protein 3 isoform d; NC, negative control; OD, optical density; P, phosphorylated.

detect the expression levels of Ki67 and cleaved caspase-3 in subcutaneous tumor tissues. The results demonstrated that the protein expression levels of cyclin D1 and Ki67 were higher in the IC53d overexpression group compared with in the control 
A

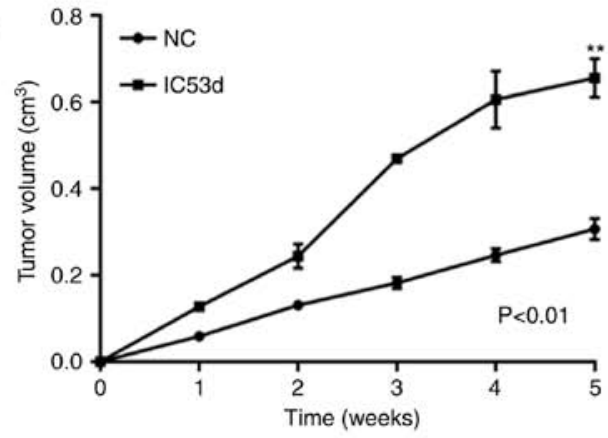

C

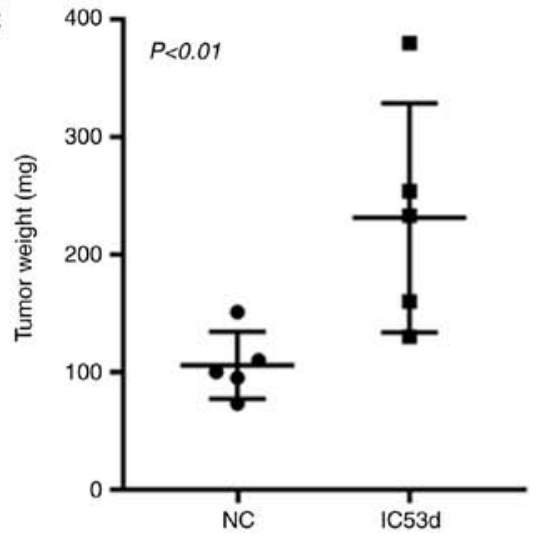

$\mathrm{E}$
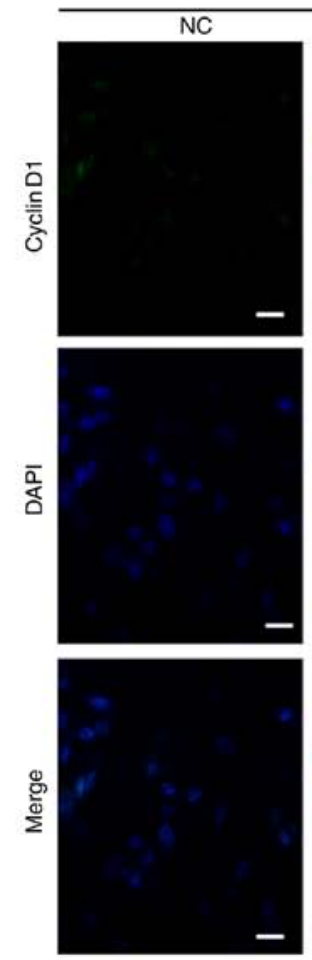

B

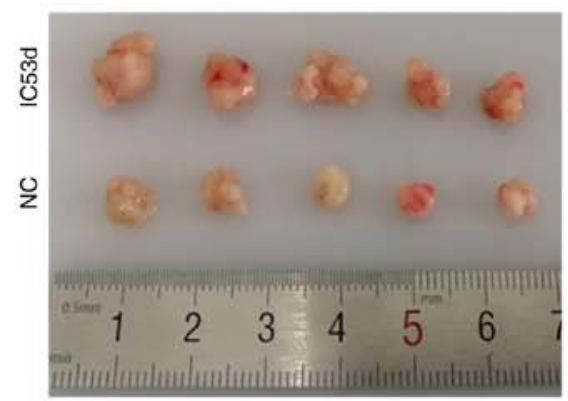

D

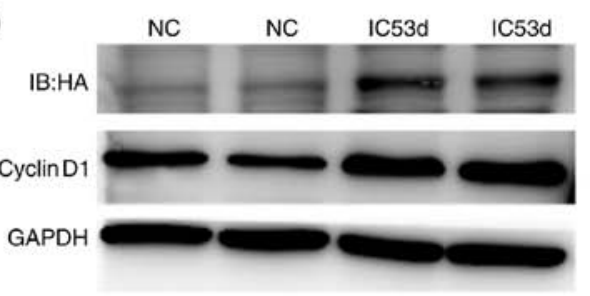

$\mathrm{F}$
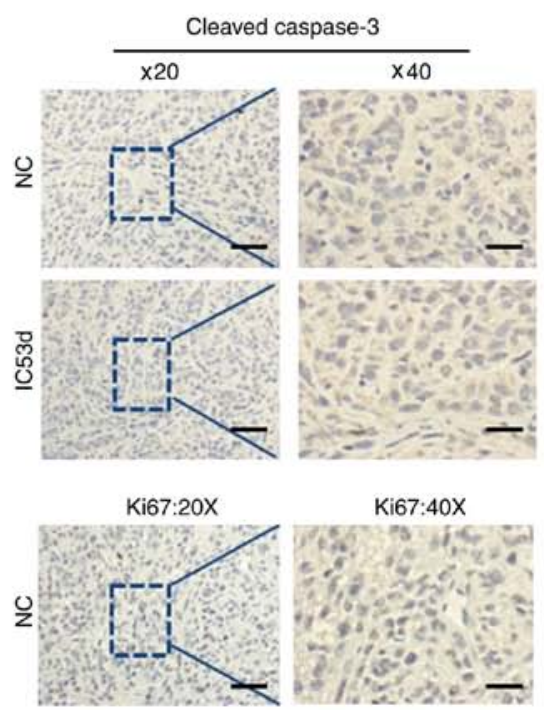

Ki67:40X
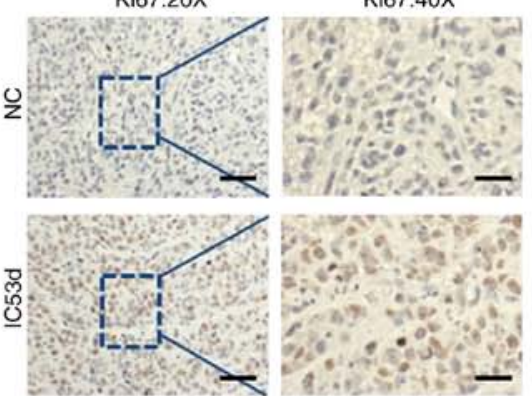

Figure 5. Xenograft models in nude mice. Xenograft models using stable MGC-803 cells were created and allowed to grow for 35 days. (A) Size of the xenografts was measured every 7 days and until the mice were sacrificed. Representative images are shown and quantified results are presented as the means \pm standard deviation, ${ }^{* *} \mathrm{P}<0.01$. (B) Representative images of the effect of IC53d overexpression are presented. (C) Average tumor weight of the different groups was compared using independent $\mathrm{t}$-test $(\mathrm{P}<0.01)$. (D) Proteins were extracted from xenografts, and protein expression levels were analyzed by western blotting. (E) Localization and expression of cyclin D1 in xenografts were detected by immunofluorescence; scale bar, $50 \mu \mathrm{m}$. (F) Protein expression levels of cleaved caspase-3 and Ki67 in xenograft tumor tissues were detected by immunohistochemistry; scale bar, $50 \mu \mathrm{m}$. HA, hemagglutinin; IB, immunoblotting; IC53d, cyclin-dependent kinase 5 regulatory subunit-associated protein 3 isoform d; NC, negative control.

group; however, there was no difference in cleaved caspase-3 expression (Fig. 5F). These results indicated that IC53d may increase the expression levels of cyclin D1 and Ki67, and promote the growth of gastric cancer in vivo. 

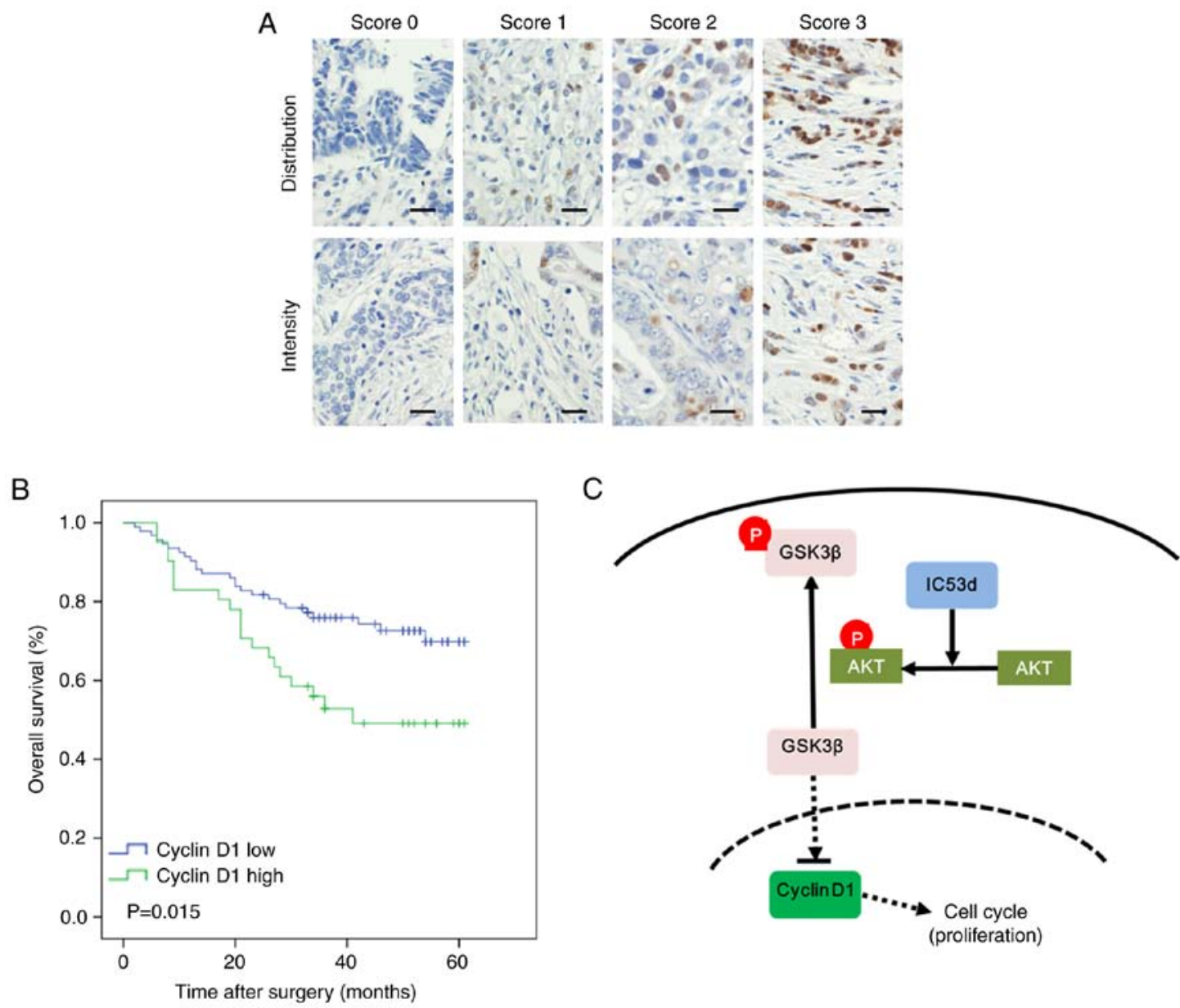

Figure 6. Immunohistochemical analysis of the expression levels of cyclin D1 in gastric cancer tissue, and its effects on prognosis. (A) Immunohistochemistry scoring of cyclin D1; scale bar, $50 \mu \mathrm{m}$. (B) Kaplan-Meier analysis of the association between cyclin D1 expression and the overall survival of patients with gastric cancer. (C) Schematic diagram summarizing the findings of the present study. IC53d promoted phosphorylation of AKT, which in turn increased phosphorylation of GSK $3 \beta$ and decreases the activity of GSK3 $\beta$, thus reducing the inhibition of cyclin D1, accelerating cell cycle progression and ultimately promoting gastric cancer cell proliferation. AKT, protein kinase B; GSK3 $\beta$, glycogen synthase kinase $3 \beta$; IC $53 \mathrm{~d}$, cyclin-dependent kinase 5 regulatory subunit-associated protein 3 isoform d; P, phosphorylated.

High cyclin Dl expression in gastric cancer is associated with a poor prognosis. IHC was also used to detect the expression levels of cyclin D1 in 134 cases of gastric cancer, and prognosis was analyzed according to the results of the immunohistochemical scores (Fig. 6A). Among the 134 patients with primary gastric cancer, cyclin D1 expression was low in $93(69.4 \%)$ and high in $41(30.6 \%)$ cases. Survival analysis, using the Kaplan-Meier method, revealed that the 5-year survival rate for gastric cancer patients with high cyclin D1 expression was $49.1 \%$, which was lower than that of patients with low cyclin D1 expression (69.8\%); this difference was statistically significant ( $\mathrm{P}=0.031$; Fig. 6B; Table II). In addition, multivariate analysis with a Cox risk regression model indicated that TNM stage $(\mathrm{P}=0.002)$ and cyclin $\mathrm{D} 1$ expression $(\mathrm{P}=0.031)$ were independent prognostic factors in patients with gastric cancer (Table II). These data suggested that cyclin D1 may be a marker of poor prognosis in patients with gastric cancer.

\section{Discussion}

Tumor occurrence is a process involving multi-step, multifactor, multi-stage and multi-gene alterations, in which abnormal cell cycle regulation and out-of-control cell proliferation are considered important mechanisms (18). Although effectiveness of the diagnosis and treatment of gastric cancer continues to increase, it remains a lethal malignancy (3). Exploring gastric cancer-specific biomarkers and effective therapeutic targets is of great importance for promoting the early diagnosis of gastric cancer and improving the efficacy of molecular targeted drugs.

C53 is a highly conserved gene in humans that is located on chromosome 17q21.32, and is widely expressed in various tissues and cells throughout the body (19). In recent years, numerous studies have reported that C53 participates in the occurrence and development of tumors; However, there is some disagreement regarding the role C53 serves in tumors. Stav and Sandbank (12) reported that the expression levels of C53 are increased in most lung cancer tissues, and that when the protein levels of C53 in tissues exceed the levels of receptor for advanced glycation end products protein, the tissues exhibit cancerous properties. It has been suggested that C53 may serve a cancer-promoting role in the development of lung cancer; however, in other studies, C53 exhibits opposite effects. In head and neck squamous cell carcinoma, Wang et al (20) revealed that the protein expression levels of 
Table II. Univariate and multivariate analyses of OS for patients with gastric cancer.

\begin{tabular}{|c|c|c|c|c|c|c|}
\hline \multirow[b]{2}{*}{ Variable } & \multicolumn{3}{|c|}{ Univariate analysis } & \multicolumn{3}{|c|}{ Multivariate analysis } \\
\hline & 5-year OS (\%) rate & Log-rank test & P-value & HR & $95 \% \mathrm{CI}$ & P-value \\
\hline Sex & & 0.668 & 0.414 & & & \\
\hline Male & 68.6 & & & & & \\
\hline Female & 59.3 & & & & & \\
\hline Age (years) & & 0.036 & 0.849 & & & \\
\hline$>60$ & 64.3 & & & & & \\
\hline$\leq 60$ & 60.8 & & & & & \\
\hline Tumor size $(\mathrm{cm})$ & & 2.635 & 0.105 & & & \\
\hline$>5$ & 58.2 & & & & & \\
\hline$\leq 5$ & 66.9 & & & & & \\
\hline Degree of differentiation & & 3.897 & 0.048 & 1.859 & $0.917-3.771$ & 0.086 \\
\hline Well/moderate & 75.4 & & & & & \\
\hline Poor/not differentiated & 57.4 & & & & & \\
\hline Depth of invasion & & 6.545 & 0.011 & & & \\
\hline $\mathrm{T} 1+\mathrm{T} 2$ & 85.7 & & & & & \\
\hline $\mathrm{T} 3+\mathrm{T} 4$ & 60.0 & & & & & \\
\hline Lymph node metastasis & & 6.661 & 0.010 & & & \\
\hline Negative & 94.7 & & & & & \\
\hline Positive & 58.3 & & & & & \\
\hline Distant metastasis & & 15.485 & $<0.0001$ & & & \\
\hline Negative & 68.1 & & & & & \\
\hline Positive & 28.6 & & & & & \\
\hline TNM stage & & 13.220 & $<0.0001$ & 4.638 & $1.792-12.008$ & 0.002 \\
\hline $\mathrm{I}+\mathrm{II}$ & 85.3 & & & & & \\
\hline III+IV & 52.8 & & & & & \\
\hline Cyclin D1 expression & & 5.895 & 0.015 & 1.916 & $1.060-3.462$ & 0.031 \\
\hline Low & 69.8 & & & & & \\
\hline High & 49.1 & & & & & \\
\hline
\end{tabular}

CI, confidence interval; HR, hazard ratio; OS, overall survival; TNM, tumor-node-metastasis.

C53 are significantly reduced, and that downregulation of C53 promotes the invasion and migration of head and neck squamous cell carcinoma cells, growth of nude mouse-transplanted tumors and the formation of new blood vessels. Furthermore, in the same tumor, C53 may serve a different role; for example, Mak et al (13) detected the expression levels of C53 in 67 cases of hepatocellular carcinoma (HCC) and demonstrated that C53 is highly expressed in HCC. An in vitro cell assay revealed that C53 promotes the invasion and migration of HCC cells by activating p21 and protease, and downregulating expression of the tumor suppressor gene p14. However, Zhao et al (14) reported that the expression levels of C53 are lower in HCC tissues and HCC cell lines, and that low C53 expression is significantly associated with poor prognosis. Therefore, C53 serves distinct roles in various tumor types and participates in several classic tumor signaling pathways. However, it is currently unknown as to whether $\mathrm{C} 53$ expression and functional differences in distinct tumor types are associated with selective cleavage variants of
C53. IC53 is an isoform of C53 that is mainly expressed in vascular endothelial cells (21), which mediates the proliferation of vascular endothelial cells. Chen et al (22) revealed that the expression levels of IC53 are closely associated with the stage and depth of invasion of colorectal adenocarcinoma. Xie et al (23) suggested that the isoform IC53-2 of the mouse C53 also regulates cell proliferation.

According to the NCBI (Gene ID: 80279), IC53d is structurally different from other isoforms in that it has a specific sequence at the tail end; therefore, the effects of IC53d on gastric cancer were explored. Notably, IC53d was upregulated in gastric cancer and was associated with the T-stage of tumors. Through in vitro and in vivo assays, it was revealed that overexpression of IC53d significantly promoted the growth of AGS and MGC-803 gastric cancer cells. Abnormal cell cycle control leads to the unlimited proliferation of cancer cells (24), and the cell cycle transition from $G_{1}$ to $S$ phase is a key step in the cell cycle, which serves a key role in biological 
processes, including cell proliferation, terminal differentiation, senescence and cell death. Furthermore, cyclin D1 is the key molecule required for cells to enter the $S$ phase (25-27).

In the present study, flow cytometric analysis demonstrated that upregulation of IC53d increased the number of cells in $\mathrm{S}$ phase. For this reason, the expression levels of cyclin D1 were detected; the results revealed that overexpression of the IC53d gene promoted cyclin D1 expression. It has previously been reported that GSK3 $\beta$ phosphorylates cyclin D1, whereas AKT inactivates GSK $3 \beta$ and thus positively regulates $\mathrm{G}_{1} / \mathrm{S}$ cell cycle progression, resulting in increased cyclin D1 expression and promotion of cell cycle progression (28). The present study demonstrated that upregulation of IC53d increased the phosphorylation levels of AKT and GSK3 $\beta$, which further validated the mechanism underlying upregulation of cyclin D1 expression. In addition, IHC was used to detect the expression of cyclin D1 in 134 cases of gastric cancer; the results revealed that high cyclin D1 expression was a poor prognostic factor in patients with gastric cancer, further validating that IC53d serves a cancer-promoting role in gastric cancer and has a clear association with cyclin D1. A schematic diagram, which summarized these findings is presented in Fig. 6C.

In conclusion, the present results indicated that IC53d promoted the phosphorylation of AKT and GSK3 $\beta$, which in turn may increase the expression of cyclin D1, thus inducing $\mathrm{G}_{1} / \mathrm{S}$ phase transition, accelerating cell cycle progression, enhancing proliferation of gastric cancer cells, and promoting progression of gastric cancer. In addition, high cyclin D1 expression was revealed to be a risk factor for poor prognosis in patients with gastric cancer. IC53d may serve a role as a pro-cancerous factor in gastric cancer, thus suggesting that IC53d may be a potential novel target for the treatment of gastric cancer; however, further large-scale clinical experimental studies are required.

The presen study had the following limitations: IC53d has homologous sequences with other splice variants of C53; therefore, stably transfected cells in which IC53d was specifically knocked out could not be obtained. Therefore, the presen study focused on the effects of IC53d overexpression on gastric cancer cells. Furthermore, all isoforms share some sequence homology, particularly isoform e, which contains identical sequences to all isoforms of C53 (isoform e is included in all isomers); therefore, it may not be possible to analyze the association between IC53d and other C53 isoforms.

\section{Acknowledgements}

The authors would like to thank the Key Laboratory of Ministry of Education of Gastrointestinal Cancer and the Key Laboratory of Tumor Microbiology, Fujian Medical University for providing experimental equipment and technical support.

\section{Funding}

The present study was supported in part by the following foundations: The National Natural Science Foundation of China (grant no. 81871899), the Science Foundation of the Fujian Province, China (grant no. 2018J01307), the Startup Fund for Scientific Research, Fujian Medical University (grant no. 2016QH024), the Scientific and Technological
Innovation Joint Capital Projects of Fujian Province (grant no. 2016Y9031), the Minimally Invasive Medical Center of Fujian Province (grant no. 2011708), and the Natural Science Foundation of Fujian Province (grant no. 2016J01463).

\section{Availability of data and materials}

The datasets used and/or analyzed during the current study are available from the corresponding author on reasonable request.

\section{Authors' contributions}

JXL, XSX and XFW contributed equally to this article and should be considered co-first authors. CHZ, PL and CMH conceived and designed the study. JXL, XSX and XFW performed the experiments. SLQ, JWX, JBW, JL, QYC, LLC, ML and RHT analyzed and interpreted the data. JXL, XSX and XFW drafted the manuscript. All authors approved the final version of the article to be published.

\section{Ethics approval and consent to participate}

All procedures performed involving human participants were in accordance with the ethical standards of the institutional research committee, and with the 1964 Helsinki declaration and its later amendments or comparable ethical standards. All applicable international guidelines for the care and use of animals were followed. Informed consent was obtained from all individual participants included in the study. The presen study was reviewed and approved by the Ethics Committee of the Fujian Medical University Union Hospital. The animal study was approved by the Ethics Committee of Fujian Medical University/Laboratory Animal Center.

\section{Patient consent for publication}

Written informed consent was obtained from patients.

\section{Competing interests}

The authors declare that they have no competing interests.

\section{References}

1. Ferlay J, Soerjomataram I, Dikshit R, Eser S, Mathers C, Rebelo M, Parkin DM, Forman D and Bray F: Cancer incidence and mortality worldwide: Sources, methods and major patterns in GLOBOCAN 2012. Int J Cancer 136: E359-E386, 2015.

2. Karimi P, Islami F, Anandasabapathy S, Freedman ND and Kamangar F: Gastric cancer: Descriptive epidemiology, risk factors, screening, and prevention. Cancer Epidemiol Biomarkers Prev 23: 700-713, 2014.

3. Papenfuss WA, Kukar M, Oxenberg J, Attwood K, Nurkin S, Malhotra U and Wilkinson NW: Morbidity and mortality associated with gastrectomy for gastric cancer. Ann Surg Oncol 21: 3008, 2014.

4. Wöhrer SS, Raderer M and Hejna M: Palliative chemotherapy for advanced gastric cancer. Ann Oncol 15: 1585-1595, 2004.

5. Chen L, Yang H, Yi Z, Jiang L, Li Y, Han Q, Yang Y, Zhang Q, Yang Z, Kuang Y, et al: LncRNA GAS5 regulates redox balance and dysregulates the cell cycle and apoptosis in malignant melanoma cells. J Cancer Res Clin Oncol, 2018.

6. Zhang LL, Hu D and Zou LH: Low expression of IncRNA MEG3 promotes the progression of oral squamous cell carcinoma by targeting miR-21. Eur Rev Med Pharmacol Sci 22: 8315-8323, 2018. 
7. Tu X, Hong D, Jiang Y, Lou Z, Wang K, Jiang Y and Jin L: FH535 inhibits proliferation and migration of colorectal cancer cells by regulating CyclinA2 and Claudin1 gene expression. Gene 690: 48-56, 2018.

8. Tsai LH, Delalle I, Caviness VS Jr, Chae T and Harlow E: p35 is a neural-specific regulatory subunit of cyclin-dependent kinase 5. Nature 371: 419-423, 1994.

9. Wu J, Jiang H, Luo S, Zhang M, Zhang Y, Sun F, Huang S and $\mathrm{Li} \mathrm{H}$ : Caspase-mediated cleavage of C53/LZAP protein causes abnormal microtubule bundling and rupture of the nuclear envelope. Cell Res 23: 691-704, 2013.

10. Wang X, Ching YP, Lam WH, Qi Z, Zhang M and Wang JH: Identification of a common protein association region in the neuronal Cdk5 activator. J Biol Chem 275: 31763-31769, 2000.

11. Lew J, Beaudette K, Litwin CM and Wang JH: Purification and characterization of a novel proline-directed protein kinase from bovine brain. J Biol Chem 267: 13383-13390, 1992.

12. Stav D, Bar I and Sandbank J: Usefulness of CDK5RAP3, CCNB2, and RAGE genes for the diagnosis of lung adenocarcinoma. Int J Biol Markers 22: 108-113, 2007.

13. Mak WY, Lai WL, Zhou Y, Li M, Ng OL and Ching YP: CDK5RAP3 is a novel repressor of p14 ${ }^{A R F}$ in hepatocellular carcinoma cells. PLoS One 7: e42210, 2012.

14. Zhao J, Pan K, Li J, Chen YB, Chen JG, Lv L, Wang DD, Pan QZ, Chen MS and Xia JC: Identification of LZAP as a new candidate tumor suppressor in hepatocellular carcinoma. PLoS One 6: e26608, 2011.

15. Amin MB, Edge S, Greene F, Byrd DR, Brookland RK, Washington MK, Gershenwald JE, Compton CC, Hess KR, Sullivan DC, et al: AJCC Cancer Staging Manual. 8th edition. New York, Springer, 2016.

16. Livak KJ and Schmittgen TD: Analysis of relative gene expression data using real-time quantitative PCR and the $2^{-\Delta \Delta C_{\mathrm{T}}}$ method. Methods 25: 402-408, 2001.

17. Mak GW, Chan MM, Leong VY, Lee JM, Yau TO, Ng IO and Ching YP: Overexpression of a novel activator of PAK4, the CDK5 kinase-associated protein CDK5RAP3, promotes hepatocellular carcinoma metastasis. Cancer Res 71: 2949-2958, 2011.

18. Marlowe JL and Puga A: Aryl hydrocarbon receptor, cell cycle regulation, toxicity, and tumorigenesis. J Cell Biochem 96 $1174-1184,2010$.
19. Ching YP, Pang AS, Lam WH, Qi RZ and Wang JH: Identification of a neuronal Cdk5 activator-binding protein as Cdk5 inhibitor. J Biol Chem 277: 15237-15240, 2002.

20. Wang J, An H, Mayo MW, Baldwin AS and Yarbrough WG: LZAP, a putative tumor suppressor, selectively inhibits NF-kappaB. Cancer Cell 12: 239-251, 2007.

21. Chen J, Liu B, Liu Y, Han Y, Yu H, Zhang Y, Lu L, Zhen Y and Hui R: A novel gene IC53 stimulates ECV304 cell proliferation and is upregulated in failing heart. Biochem Biophys Res Commun 294: 161-166, 2002.

22. Chen J, Shi Y, Li Z, Yu H, Han Y, Wang X, Sun K, Yang T, Lou K, Song Y, et al: A functional variant of IC53 correlates with the late onset of colorectal cancer. Mol Med 17: 607-618, 2011.

23. Xie YH, He XH, Tang YT, Li JJ, Pan ZM, Qin WX, Wan DF and Gu JR: Cloning and characterization of human IC53-2, a novel CDK5 activator binding protein. Cell Res 13: 83-91, 2003.

24. Motokura T, Bloom T, Kim HG, Jüppner H, Ruderman JV, Kronenberg HM and Arnold A: A novel cyclin encoded by a $b c l l-$ linked candidate oncogene. Nature 350: 512-515, 1991.

25. Zhou JX, Niehans GA, Shar A, Rubins JB, Frizelle SP and Kratzke RA: Mechanisms of G1 checkpoint loss in resected early stage non-small cell lung cancer. Lung Cancer 32: 27-38, 2001.

26. Kamb A, Gruis NA, Weaverfeldhaus J, Liu Q, Harshman K, Tavtigian SV, Stockert E, Day RS III, Johnson BE and Skolnick MH: A cell cycle regulator potentially involved in genesis of many tumor types. Science 264: 436-440, 1994.

27. Moghaddam SJ, Haghighi EN, Samiee S, Shahid N, Keramati AR, Dadgar S and Zali MR: Immunohistochemical analysis of p53, cyclinD1, RB1, c-fos and N-ras gene expression in hepatocellular carcinoma in Iran. World J Gastroenterol 13: 588-593, 2007.

28. Liu L, Zhang H, Shi L, Zhang W, Yuan J, Chen X, Liu J, Zhang Y and Wang Z: Inhibition of Racl activity induces G1/S phase arrest through the GSK3/cyclin D1 pathway in human cancer cells. Oncol Rep 32: 1395-1400, 2014.

(7) $(-)$ This work is licensed under a Creative Common Attribution-NonCommercial-NoDerivatives 4.0 International (CC BY-NC-ND 4.0) License. 